\title{
Observation of Water Penetration into Cracked and Water Repellent SHCC after Imposed Strain by Means of Neutron Radiography
}

\author{
P. G. Wang' ${ }^{1}$, F. H. Wittmann ${ }^{1,2 *}$, P. Zhang ${ }^{1}$, E. H. Lehmann ${ }^{3}$ and T. J. Zhao ${ }^{1}$ \\ ${ }^{1}$ Department of Civil Engineering, Qingdao Technological University, 266033 Qingdao, China \\ ${ }^{2}$ Aedificat Institute Freiburg, 79100 Freiburg, Germany \\ ${ }^{3}$ Neutron Imaging \& Activation Group, Paul Scherrer Institute, CH-5232 Villigen, Switzerland \\ ${ }^{*}$ Corresponding author: F. H. Wittmann, e-mail: wittmann@aedificat.de
}

\begin{abstract}
Huge strain capacity of SHCC under tensile stress can be reached by multiple crack formation, while the cracks remain bridged by fibers. Under protective conditions the full strain capacity can be used in practice. In this contribution it is shown that even at comparatively modest imposed strain cracks are formed, which may transport water and ions dissolved in water deep into structural elements made of SHCC. One way to reduce water penetration into cracked SHCC has been investigated, the use of an integral water repellent cement-based matrix. It is shown that in this way water penetration is significantly reduced and hence durability is increased.
\end{abstract}

Keywords: Water penetration; Multi-cracks; Strain Hardending Cementitious Composite (SHCC); Neutron radiography . 


\section{1}

\section{Introduction}

Durability of cement-based materials and in particular of steel reinforced cement-based materials depends strongly on the penetration rate of water and ions dissolved in water. It has been shown that cracks are preferential pathways for water and chloride dissolved in water to penetrate deep into concrete [1-7]. It could be shown that Neutron Radiography is a particular powerful method to observe water penetration into porous materials such as concrete and into cracks in particular.

SHCC (Strain Hardening Cement-based Composite) is often called to be a pseudo-plastic material. That means that a huge strain capacity is reached by multiple crack formation while the cracks are bridged by fibers [8-10]. If such a material is applied under protection, without exposure to water or salt solutions, the full strain capacity can be exploited. In cases where the material under imposed strain is exposed to natural environment and to contact with seawater for instance, the durability becomes an important issue and service life of a structure may be seriously reduced by crack formation. In this case the huge strain capacity can be used partly only. The maximum allowable strain will not be given by the materials mechanical properties as such but rather by the rate of water and chloride penetration. In this contribution it is shown that even at an imposed strain of $0.5 \%$ water can penetrate deep into the material in a short time. One way to take advantage of the strain capacity is water repellent treatment. One major aim of this project was to study the influence of integral water repellent treatment of SHCC on water penetration into the fine cracks, which are formed under imposed strain.

\section{Materials and Methods / Experimental}

\subsection{Materials and Preparation of Specimens}

The composition of SHCC has been optimized for these test series by varying the amount of the different components in a systematic way. Finally the following composition was chosen: $550 \mathrm{~kg} / \mathrm{m}^{3}$ ordinary Portland cement Type $42.5,650 \mathrm{~kg} / \mathrm{m}^{3}$ local fly ash, $550 \mathrm{~kg} / \mathrm{m}^{3}$ sand with a maximum grain size of $0.3 \mathrm{~mm}$, and $395 \mathrm{~kg} / \mathrm{m}^{3}$ water. To the fresh mix $26 \mathrm{~kg} / \mathrm{m}^{3}$ of commercial PVA fibres with a diameter of $40 \mu \mathrm{m}$ produced by Kuraray Company were added. The density and mechanical properties of the fibers are shown in Table 1. In addition, integral water repellent SHCC has been prepared by adding $2.0 \%$ (related to the mass of binder) silane emulsion to the fresh mix. After compaction in steel forms all specimens were allowed to harden in the laboratory under wet burlap for 24 hours. Then the steel form has been removed and the specimens were stored until an age of 21 days in a moist curing room $\left(\mathrm{T} \approx 20^{\circ} \mathrm{C}\right.$, $\mathrm{RH} \geq 95 \%$ ).

In this project, dumbbell shaped specimens with a thickness of $30 \mathrm{~mm}$ and an overall length of $330 \mathrm{~mm}$ have been cast in steel moulds. The width at both ends is $90 \mathrm{~mm}$ and the centre part with a length of $120 \mathrm{~mm}$ has a width of $60 \mathrm{~mm}$. The shape and the dimensions of the SHCC samples are given in Fig. 1. The centre part, which has been under uniform tensile stress, had the following size: 120 $\mathrm{mm} \times 60 \mathrm{~mm} \times 30 \mathrm{~mm}$. To determine capillary absorption of water by means of neutron radiography, the centre part has been cut out of the dumbbell specimen with a diamond saw after a certain tensile strain had been applied.

\subsection{Multiple Crack Formation at Differ- ent Levels of Applied Strain}

The samples were taken out of the curing room at an age of 21 days. Then the specimens were fixed in a stiff steel frame. In a direct tension test different strain levels could be imposed. The following strain levels were selected: $0.5 \%, 1.0 \%, 1.5 \%$ and $2.0 \%$. These chosen strain levels were imposed to both neat and integral water repellent SHCC samples. The maximum load was kept constant for 10 minutes before unloading again.

Table 1: Density and mechanical properties of the PVA fibres used in this project.

\begin{tabular}{|l|l|l|l|}
\hline $\begin{array}{l}\text { Density, } \\
\mathrm{g} / \mathrm{cm}^{3}\end{array}$ & $\begin{array}{l}\text { Elastic } \\
\text { Modulus, } \\
\text { GPa }\end{array}$ & $\begin{array}{l}\text { Ultimate } \\
\text { strain, } \\
\%\end{array}$ & $\begin{array}{l}\text { Tensile } \\
\text { strength, } \\
\text { MPa }\end{array}$ \\
\hline 1.3 & 42.0 & 7.0 & 1600 \\
\hline
\end{tabular}

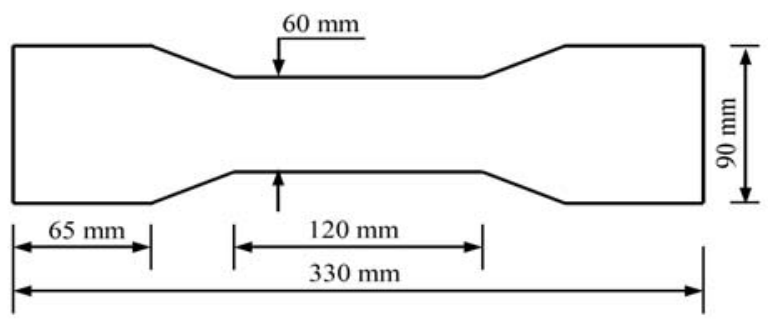

Figure 1: Geometry and dimensions of the dumbbell specimens used in this project. 


\section{$3 \quad$ Results and Discussion}

\subsection{Water Penetration into Neat SHCC after Exposure to Different Strain Levels}

The process of water penetration into SHCC exposed to different levels of tensile strain has been made visible by neutron radiography. First neutron images have been taken on unloaded specimens for reference. Selected images taken at 15, 45 and 90 minutes of capillary absorption are shown in Fig. 2. As one could have expected SHCC specimens which have not been under tensile stress absorbed very little water even after contact with the liquid for 45 minutes. A quantitative analysis shows that a small amount of water penetrates into the porous material nevertheless as shown in Fig. 3. From results shown in Fig. 3 a coefficient of capillary penetration $\mathrm{B}$ can be determined.

$$
\mathrm{W}(\mathrm{t})=\mathrm{B} \mathrm{t}^{1 / 2}
$$

B was found to be approximately $0.004 \mathrm{~m} / \mathrm{h}^{1 / 2}$. It can be concluded that SHCC has a very low coefficient of capillary penetration as compared to ordinary concrete. $\mathrm{B}$ was found to be even lower after deep surface impregnation of cement-based materials with liquid silane.

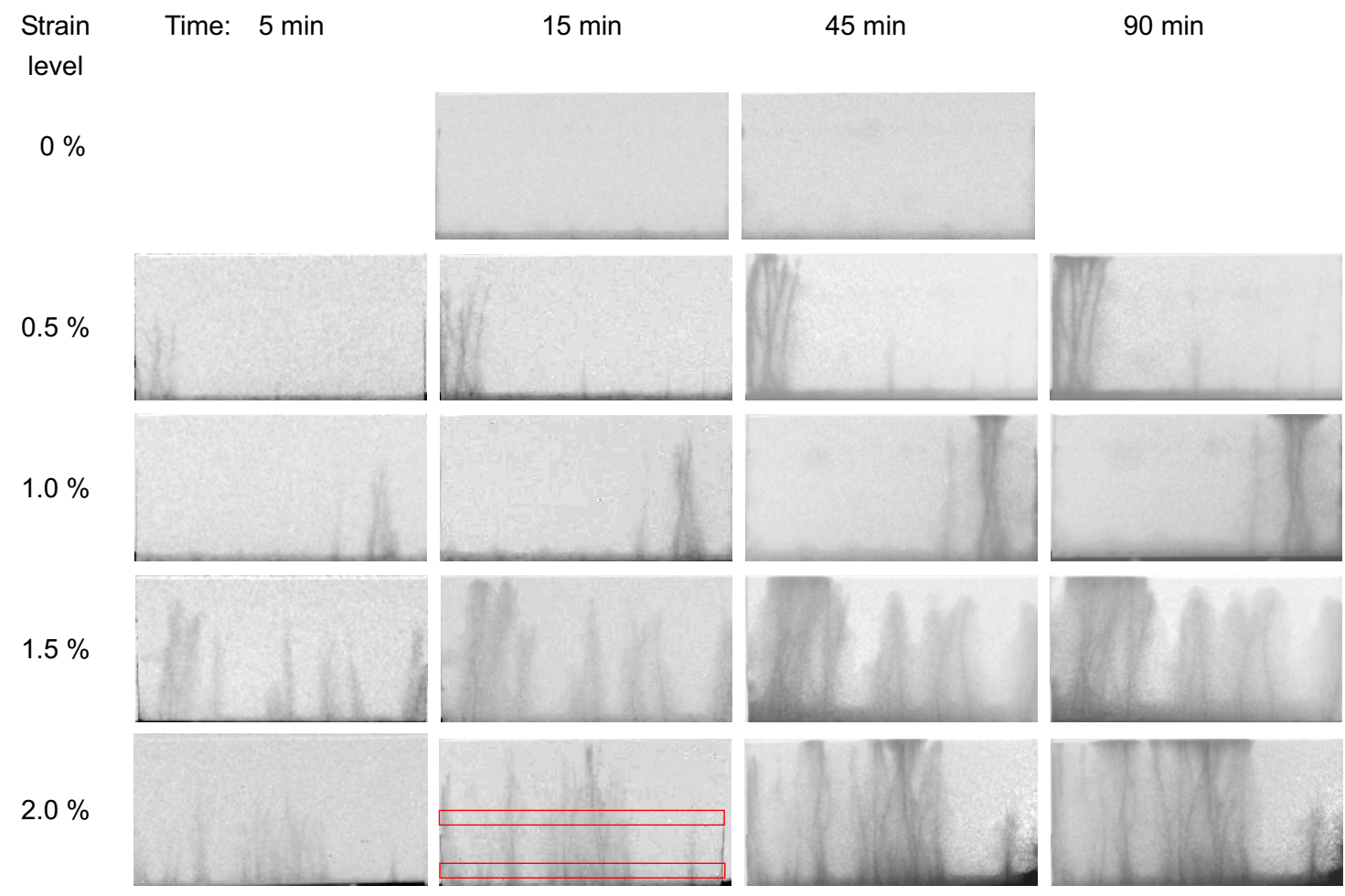

Figure 2: $\quad$ Neutron images showing water penetration into neat SHCC after different imposed levels of tensile strain. Along the indicated two rectangular areas the water content has been determined.

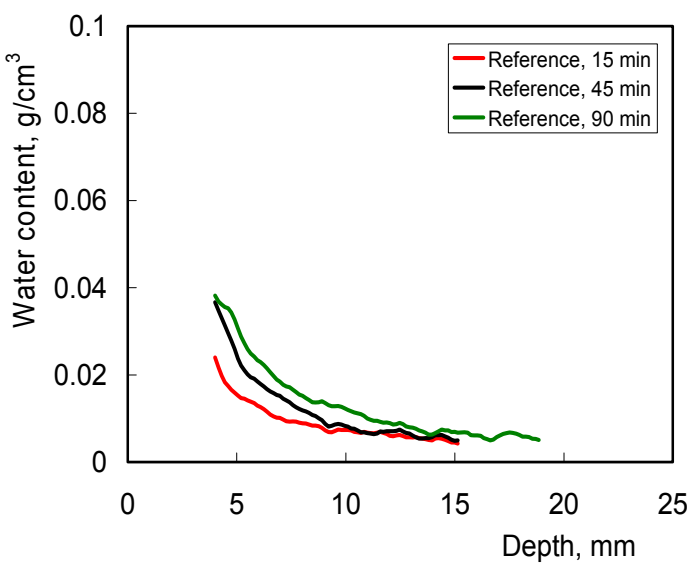

Figure 3: $\quad$ Capillary absorbed water profiles in unstrained SHCC after 15, 45 and 90 minutes of contact with water.
If the type of SHCC, which has been prepared for this project, is exposed to a maximum tensile strain of $0.5 \%$, a few cracks can be observed. The widest cracks are quickly water filled up to the height of the specimen, which is $60 \mathrm{~mm}$. Some finer cracks become visible after 15 minutes only. The moisture distribution in SHCC in contact with water has been determined quantitatively after 15 and 90 minutes in the two rectangular areas shown in Fig. 2 on the neutron image taken after 15 minutes on a SHCC specimen which was exposed to a tensile strain of $2 \%$. The moisture profiles along the two levels are shown in Fig. 4. In this case water profiles as observed after 15 and 90 minutes of capillary absorption on specimens, which were exposed 


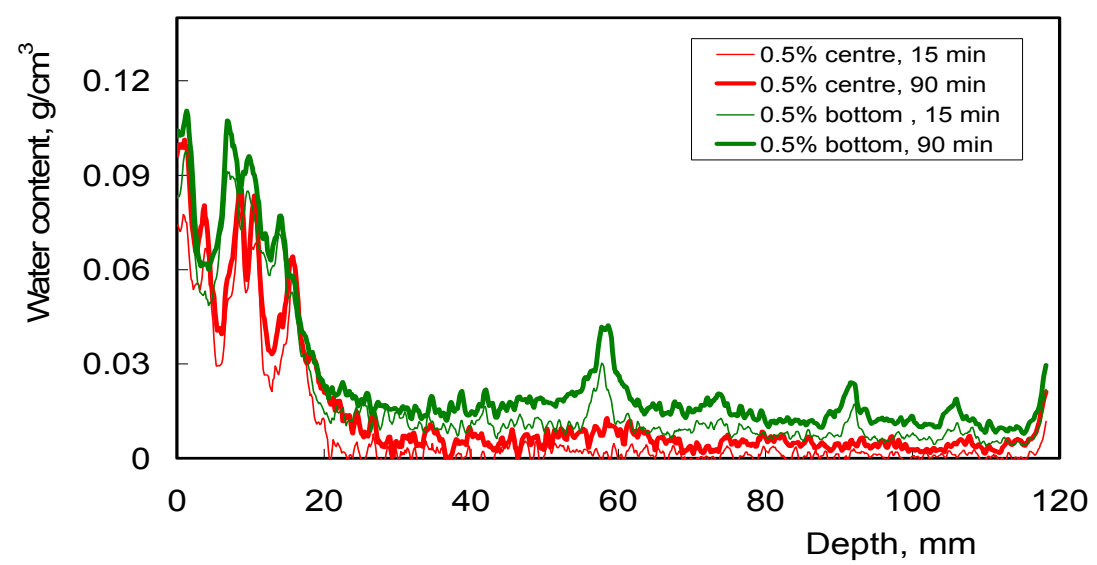

Figure 4: Water content in horizontal direction in the center and the bottom of cracked SHCC after imposed tensile strain of $0.5 \%$.

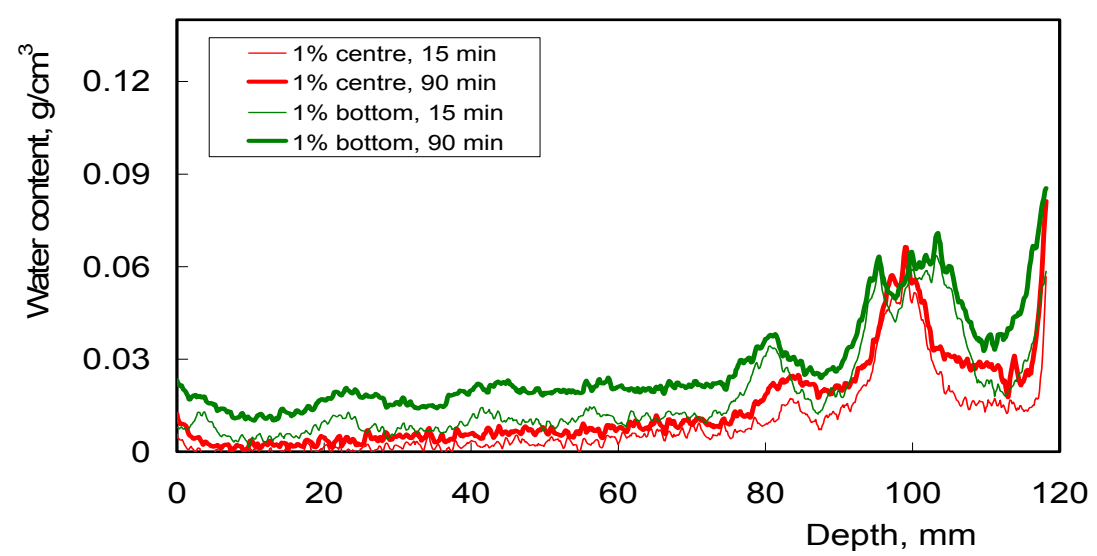

Figure 5: Water content in horizontal direction in the center and at the bottom of cracked SHCC after imposed tensile strain of $1 \%$.

to a tensile strain of $0.5 \%$ are shown. Obviously the lower part has absorbed more water than the center of the specimen. The wide cracks, which reach the upper surface, soon contain significantly more water than fine cracks. From the volume of the penetrated water the width of the cracks can be calculated. In Fig. 5 the corresponding moisture profiles of a specimen, which has been exposed to $1 \%$ strain under tension are shown. Again the capillary absorption can be observed by the time-dependent rise of the water content in the areas without cracks. The corresponding water profiles as determined on samples, which have experienced a strain of $1.5 \%$ are shown in Fig. 6. Under these conditions the cracks became wider and they absorb more water. But the damage in the regions near the cracks is also gradually damaged and these samples absorb much more water as compared with the specimen which was strained up to $0.5 \%$ only. Finally the water up-take in SHCC, which has experienced a tensile strain of $2 \%$ is also distributed over the entire vol- ume and not concentrated on the water filled cracks.

These results underline the fact that SHCC has an extreme strain capacity. If the mechanical properties are of interest in a given application exclusively, then one can take full advantage of the strain capacity. If durability is an issue, however, the ultimate strain, which may be allowed, is very limited.

\subsection{Water Penetration into Integral Water Repellent SHCC}

By adding silane emulsion to SHCC an integral water repellent cementitious matrix can be produced. In section 3.1 we have seen that water penetrates into the fine cracks, which are formed at high strain due to the so-called pseudo ductility. If the matrix is made water repellent, the water penetration into the cracks should be reduced at least significantly. Therefore tests have been run with integral water repellent SHCC. 


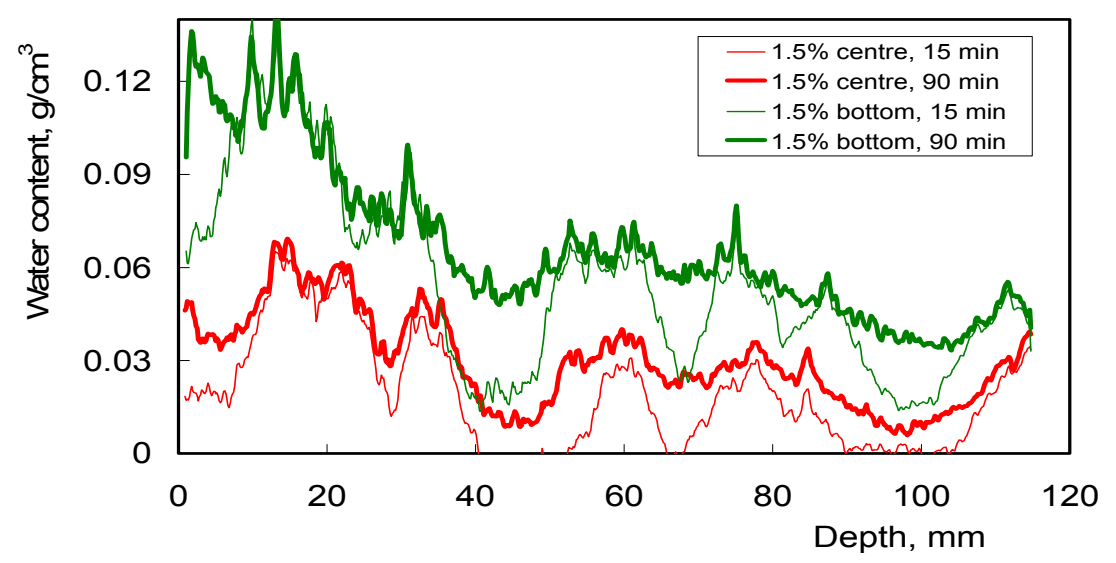

Figure 6: Water content in horizontal direction in the center and the bottom of cracked SHCC after imposed tensile strain of $1.5 \%$.

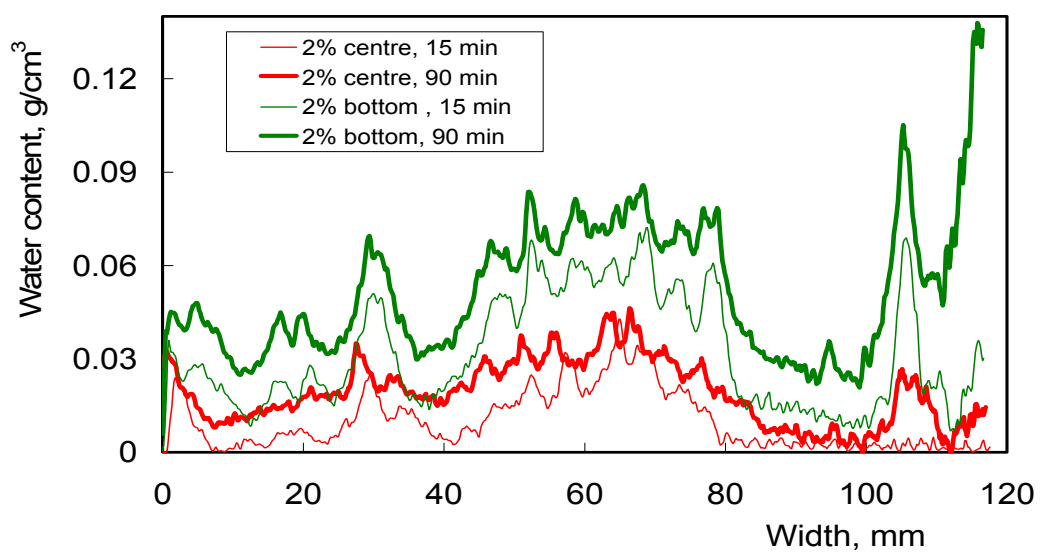

Figure 7: Water content in horizontal direction in the center and at the bottom of cracked SHCC after imposed tensile strain of $2.0 \%$.

Typical results are shown in Fig. 8. The specimens which have not been exposed to strain absorb practically no water during 90 minutes of contact with the liquid. Even after application of $0.5 \%$ strain traces a small quantity of water can be observed in the cracks. When a strain of $1.5 \%$ was imposed, cracks begin to absorb more important amounts of water.

In Fig. 8 the water profile in a specimen after application $0.5 \%$ strain is shown. Compared with results shown in Fig. 4 less water enters the zones without crack and the cracks absorb significantly less water as well. In Fig. 10 the water profiles as measured on SHCC, which has been strained up to $1.5 \%$ are shown. We can observe that under these conditions the cement-based matrix of SHCC still does not absorb water and the amount of water penetrating the cracks is significantly less as can be checked by comparing Fig. 6 and Fig. 10.

\section{Conclusions}

From the results presented in this contribution it can be concluded that cracks formed by imposed strain of not more than $0.5 \%$ in SHCC absorb water by capillary action. This water penetrates deep into the material. If SHCC is applied as a protective layer, a maximum strain must not be exceeded. This maximum tolerable strain is still to be determined for different types of SHCC.

Integral water repellent SHCC absorbs less water into the cement-based matrix and into cracks formed by strain under tension. When cracks are formed, they absorb less water. This is an indication that higher tensile strain will be allowable. Surface impregnation with silane after crack formation will be a promising alternative. 
Strain Time: $5 \mathrm{~min}$

$15 \min$

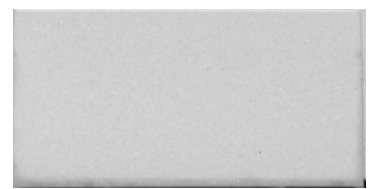

$0.5 \%$

$1.5 \%$
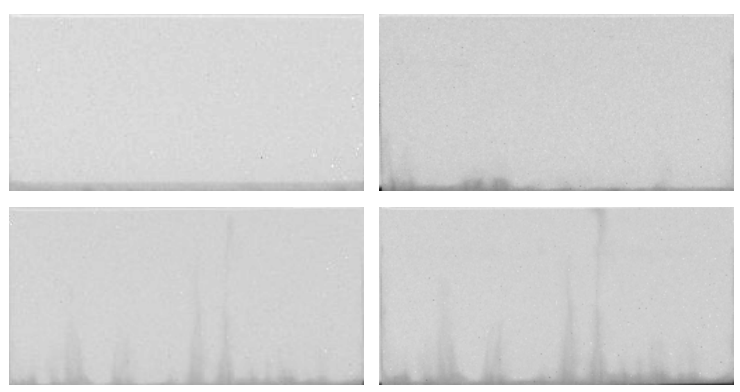

Figure 8: Neutron images of water penetration into integral water repellent SHCC after imposed different level of tensile strain.

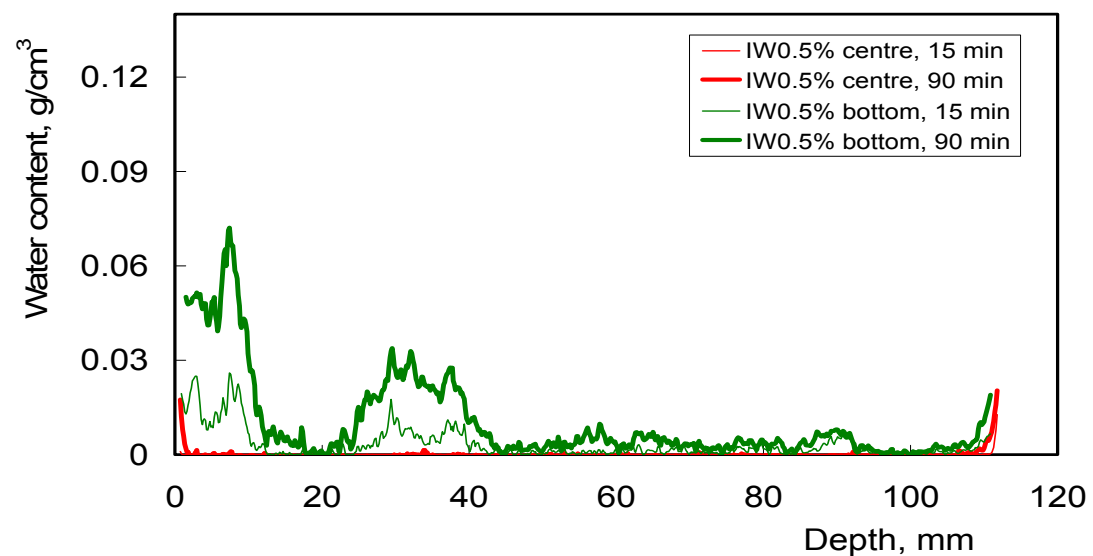

Figure 9: Water content in horizontal direction in the center and the bottom of cracked water repellent SHCC after $0.5 \%$ of tensile strain.

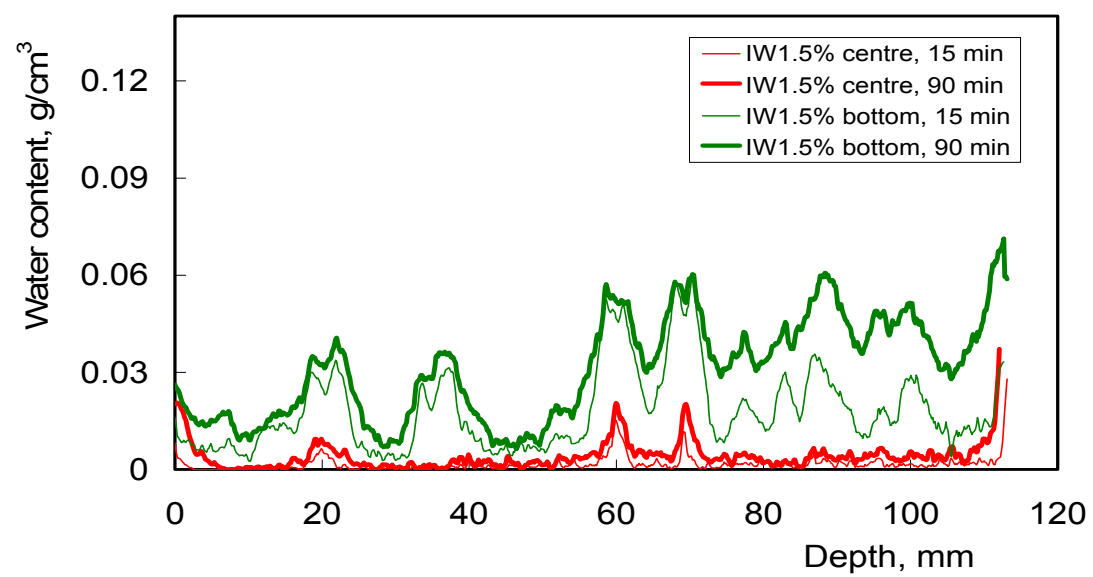

Figure 10: Water content in horizontal direction in the center and at the bottom of cracked water repellent SHCC after $1.5 \%$ of tensile strain. 


\section{Acknowledgement}

The authors gratefully acknowledge substantial support of ongoing projects by Cooperative Innovation Center of Engineering Construction and Safety in Shandong Blue Economic Zone and National Natural Science Foundation of China (nos. 51278260, 51008165 and 51108443).

\section{References}

1. F. H. Wittmann, P. Guo and T. Zhao, Influence of cracks on the efficiency of surface impregnation of concrete, Proceedings of Fifth Int. Conf. Water Repellent Treatment of Building Materials, Hydrophobe V, H. De Clercq and A. E. Charola, editors, Aedificatio Publishers (2008) pp. 287-298.

2. P. Zhang, F. H. Wittmann, T. Zhao, E. Lehmann, P. Vontobel and S. Hartmann, Observation of water penetration into water repellent and cracked cement-based materials by means of neutron radiography, Int. J. Restoration of Buildings and Monuments 15 (2009) 91-100.

3. P. Zhang, J. G. Dai, T. Zhao, F. H. Wittmann and S. Hartmann, Water repellent treatment on surface of cracked concrete under seawater exposure environment, Journal of Building Materials, 12 (2) (2009) 214-218.

4. F. H. Wittmann, T. Zhao, Z. Ren and P. Guo, Influence of surface impregnation with silane on penetration of chloride into cracked concrete and on corrosion of steel reinforcement, Int. J. Modelling, Identification and Control, 7 (2009) $135-141$.

5. P. Zhang, F. H. Wittmann, T. Zhao and E. H. Lehmann, Neutron imaging of water penetration into cracked steel reinforced concrete, Physica B: Condensed Matter, 405(7) (2010) 1866-1871.

6. F. X. Jiang, F. R. Li, T. J. Zhao and F. H. Wittmann, Study on chloride penetration into the cracked zone of reinforced concrete and effect of water repellent treatment, Concrete (2) (2011) 21-24, in Chinese.

7. P. Zhang, J. Dai, T. Zhao, F. H. Wittmann and Z. Jin, Water absorption of cracked concrete and efficiency of water repellent treatment, Journal of Building Materials 13 (1) (2010) 70-74 (in Chinese).
8. G. P. A. G. van Zijl, F. H. Wittmann, B. H. Oh, P. Kabele, R. D. Toledo Filho, E. M. R. Fairbairn, V. Slowik, A. Ogawa, H. Hoshiro, V. Mechtcherine, F. Altmann, M. D. Lepech, Durability of strain-hardening cement-based composites (SHCC), Materials and Structures, 45 (2012) 1447-1463.

9. G. P. A. G. Van Zijl and F. H. Wittmann (eds.) Durability of Strain-Hardening Fibre-Reinforced Cement-Based Composites (SHCC), State-of-the-Art Report, Rilem TC 208 HFC, SC 2, Springer Publishers, (2011).

10. G. P. A. G. van Zijl, V. Slowik, R. D. Toledo Filho, F. H. Wittmann, H. Mihashi, Comparative testing of crack formation in strain-hardening cement-based composites, (to be published)

Received March 20, 2014 
Bereitgestellt von | Lib4RI Eawag-Empa

Angemeldet

Heruntergeladen am | 22.01.19 10:07 